\title{
Investigations into the Sequential Application of Crease Resist Finish, Tannin and Cationic Reactant to Improve the Resistance of Sulphur Dyes to Oxidation
}

\author{
QURATULAIN MOHTASHIM*, AND MURIEL RIGOUT**
}

RECEIVED ON 02.02.2018 ACCEPTED ON 25.05.2018

\begin{abstract}
The importance of sulphur dyes are realized due to the fact that they offer an economical method of achieving dyeing of good color strength and acceptable fastness on cellulosic substrates. However, the main limitations associated with this class of dye are the lack of availability of bright colors and it's fading on exposure to laundering with detergent and perborates/peroxides formulations. In order to meet the growing requirements of customers regarding the higher wash fastness, garment traders are in turn demanding their suppliers to achieve these properties against single and multiple washes.

In this study, sulphur black 1 dyed cotton fabric has been aftertreated with Fixapret $\mathrm{CP}$, Bayprotect $\mathrm{Cl}$ and CC (Choline Chloride) with various sequential combinations to improve the wash fastnesss of the dyed fabric against the aggressive ISO-1O5 CO9 washing system. Sequential application of Bayprotect $\mathrm{Cl}$ followed by $\mathrm{CC}$ was found to offer a significant improvement causing a $12 \%$ reduction in percentage colour loss relating to the untreated fabric, which was comparable to the independent application of Fixapret CP with minimum deleterious effects on the hue, chroma and tensile strength of the fabric.
\end{abstract}

Key Words: Cotton, Sulphur Dye, Wash Fastness, After Treatment, Tannin, Crease Resist Finish.

\section{INTRODUCTION}

I

$\mathrm{t}$ is well-known that cotton is the most commonly used cellulosic fibre and the sulphur dye class is reported to have the highest consumption among all other colorants applied to cotton as evident from the world consumption data (Fig. 1).

The most attractive feature of sulphur dyes is their low cost which makes their application attractive for dark shades including black, navy, brown and olive [1]. These possesses moderate to good fastness which allows them to broadly satisfy the needs of industry, however, with the increasing performance demands of garment suppliers and customers, the use of these dyes is gradually declining as they are getting replaced by other dye classes [2]. A major reason for their continuing unpopularity is the environmental impact that is created by the use of the conventional reducing agent sodium sulphide, which is highly toxic to marine life and sewerage systems. 
Secondly, cellulosic goods dyed with sulphur dyes are particularly susceptible to perborate bleach-containing washing powders thus exhibiting impaired washfastness against oxidative bleaching.

With the passage of time, the developments in household laundering detergents and their impact on cellulosic fibres have been taken into consideration. The fastness properties and cross staining performance of sulphur dyed fabric are usually characterized with the help of standard ISO-1O5 CO6 benchmark. In recent times, a distinctive combination of standard detergent, a low temperature TAED (Tetraacetylethylenediamine) bleach activator has been developed which resembles modern detergent formulation and laundering practice, this is the ISO-1O5 CO9 washing protocol [3].

Cellulosic goods dyed with sulphur dyes are particularly affected by bleach-containing washing powders. The purpose of bleach (such as sodium perborate) is to help remove the stains produced by tea, coffee, fruit juice etc. and the addition of a bleach activator (such as TAED) facilitates the low temperature removal of these stains [4].

One of the most important aspects of this work was to design an after treatment formulation to improve the wash down of sulphurdyeings when exposed to

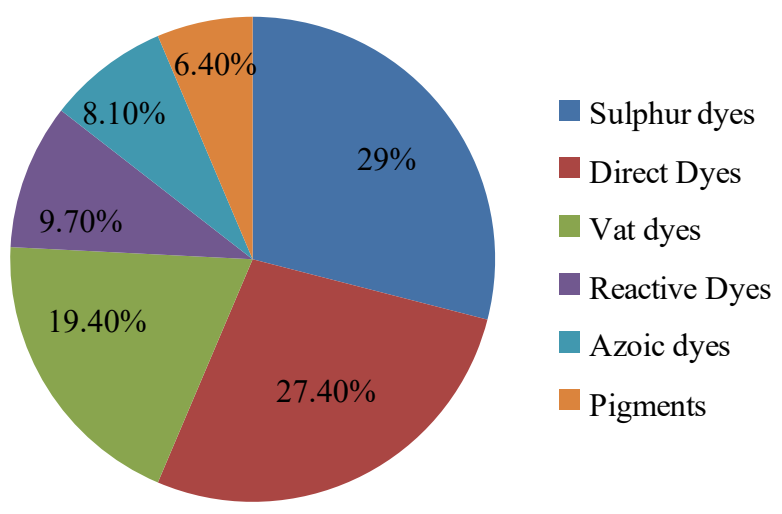

FIG. 1. SHARE OF THE WORLD DYE MARKET FOR CELLULOSIC FIBRES [1] aggressive washing system of ISO-1O5 CO9. The work done so far has produced potential solutions to improve the resistance of sulphur dyed cotton fabric against ISO-1O5 CO6 treatments. However, the effect of ISO105 CO9 washing is far more degradative to the colour, hence a further protective system is needed to be developed which could safeguard the dyed material from the highly oxidative environment produced by this washing regime. For this purpose, the sequential applications of crease resist finish (Fixapret CP), cationic reactant (CC) and tannin (Bayprotect $\mathrm{Cl}$ ) have been explored.

\section{MATERIALS AND METHOD}

\subsection{Materials}

A plain woven, bleached, 100\% cotton fabric having GSM (Grams Per Square Meter) 103 and EPI (Ends Per Inch) x PPI (Picks Per Inch) - 77x66 was used throughout the study. The fabric was generously provided by Phoenix Calico Limited. Diresul CI (Color Index) Leuco Sulphur Black 1 dye and Diresul Reducing agent D manufactured by Clariant were used. The ECE non-phosphate detergent and $92 \%$ active TAED were purchased from the SDC (Society of Dyers and Colorists), Bradford, UK. Sodium perborate tetrahydrate ( $97 \%$ active), hydrogen peroxide and sodium bicarbonate (Laboratory grade) were purchased from Aldrich Chemicals Ltd., UK.

\subsection{Dyeing Procedure}

Dyeing of cotton with a biodegradable glucose based reducing agent (Diresul Reducing Agent D) was carried out by the method prescribed by Clariant, shown in Fig. 2. The cotton fabric was introduced into a dye bath containing 5\% omf (on mass of fabric) Diresul Black RDT liquid, $25 \mathrm{~g} / \mathrm{L}$ sodium chloride, $13 \mathrm{~mL} / \mathrm{L}$ of sodium hydroxide $\left(67^{\circ} \mathrm{Tw}\right), 9 \mathrm{~g} / \mathrm{L}$ Diresul Reducing agent $\mathrm{D}$ with liquor to goods ratio (L:R) of 10:1. The dye bath was 
raised to $98^{\circ} \mathrm{C}$ at a gradient of $4^{\circ} \mathrm{C} / \mathrm{min}$ and maintained at the boil for 60 minutes. The temperature was then reduced to $50^{\circ} \mathrm{C}$.

Dyeings were washed thoroughly with cold water to remove any unfixed surface dye. The dyed fabric was then oxidised with $5 \mathrm{~g} / \mathrm{L}$ hydrogen peroxide and $1 \mathrm{~g} / \mathrm{L}$ soda ash at $40-45^{\circ} \mathrm{C}$ for 15 minutes. It was then finally soaped with $1 \mathrm{~g} / \mathrm{L}$ of non-ionic detergent at the boil for 20 minutes and then rinsed with warm and cold water. The L:R employed for oxidation and soaping was 10:1.

\subsection{After Treatment with Bayprotect Cl}

Sulphur dyed fabrics were after treated with a liquor containing 4\% omf Bayprotect $\mathrm{Cl}$ and $100 \mathrm{~g} / \mathrm{L}$ sodium sulphate. A pH of $<3.5$ was maintained with citric acid. The samples along with the liquor were treated at $98^{\circ} \mathrm{C}$ for 20 minutes with liquor to goods ratio of 10:1. The finished fabric was finally rinsed with warm and cold water and air dried. The application method is shown in Fig. 3.

\subsection{After Treatment with Fixapret CP}

Sulphur dyed fabrics were after treated with the durable press finish Fixapret $\mathrm{CP}$ in the presence of magnesium chloride (reagent grade, Aldrich Chemicals Ltd, UK.) used as a catalyst. Sulphur dyed fabric was padded with a wet pick-up of $70-80 \%$ in a solution containing Fixapret CP and magnesium chloride. The fabric was then dried at $100^{\circ} \mathrm{C}$ for $1 \mathrm{~min}$ and cured at $150^{\circ} \mathrm{C}$ for 4 minutes. Hence a PDC (Pad-Dry-Cure) method was adopted.

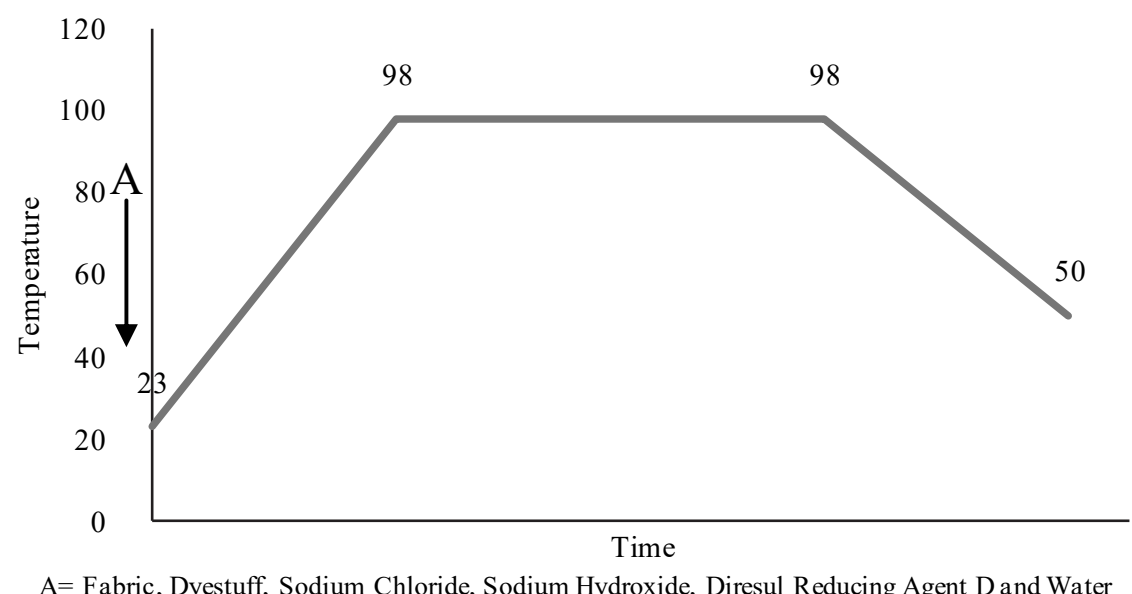

FIG. 2. SULPHUR DYEING METHOD

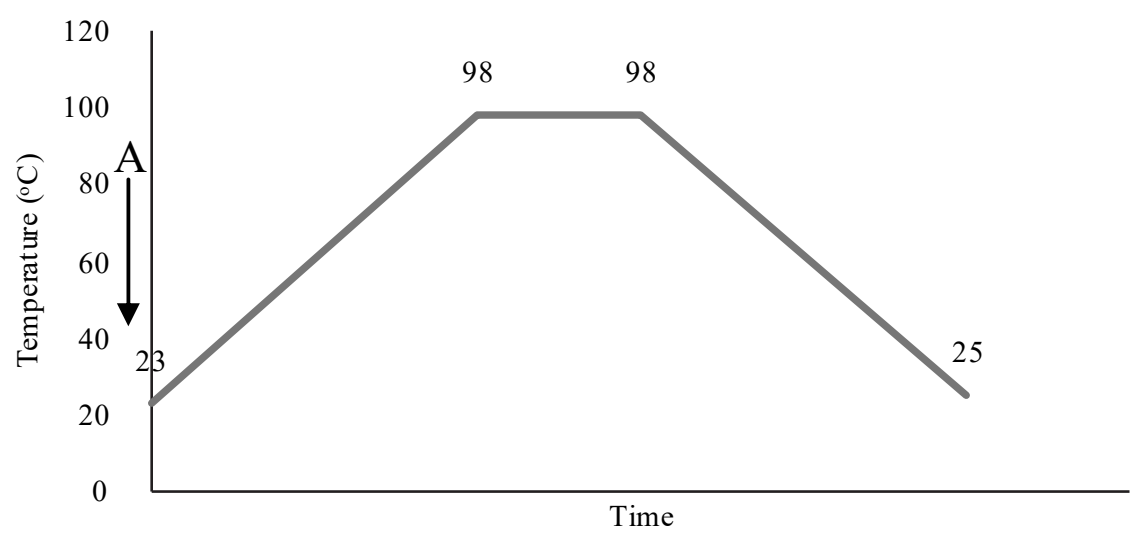

$\mathrm{A}=$ Dyed Fabric, $4 \%$ omf Bayprotect $\mathrm{Cl}, 100 \mathrm{gm} / \mathrm{L}$ Sodium Sulphate, Citric Acid to $\mathrm{pH}<3.5$ FIG. 3. AFTERTREATMENTS WITH BAYPROTECT CL 


\subsection{After Treatment with Choline Chloride}

$\mathrm{CC}$ was applied on its own and also added in different concentrations to the liquor containing Fixapret CP and magnesium chloride. The application method is the same as described above in section 2.4

\subsection{Colour Analysis}

The colorimetric data of the dyed and after treated cotton fabrics were measured using a Datacolor Spectroflash 600 spectrophotometer, with a $10^{\circ}$ standard observer and D65 illuminant, and were the average of four measurements. The K/S (Color Strength) was evaluated using the Kubelka-Munk equation, represented in Equation (1)

$\left(\frac{K}{S}\right)_{\lambda}=\frac{\left(1-R_{\lambda}\right)^{2}}{2 R_{\lambda}}$

Where $\mathrm{K}$ is the absorption coefficient, $\mathrm{S}$ is the scatter coefficient, $\mathrm{R}$ is the reflectance expressed as a fractional value at wavelength of maximum absorption $\lambda$ The $\%$ color loss of the untreated and after treated dyed fabrics after laundering were determined with the Equation (2):

$$
\% \text { Color Loss }=\frac{\frac{\mathrm{K}}{\mathrm{S}} \text { Befor Washing }-\frac{\mathrm{K}}{\mathrm{S}} \text { After Washing }}{\frac{\mathrm{K}}{\mathrm{S}} \text { BeforeWashing }} \times 100
$$

\subsection{Determination of Fastness Properties}

The color fastness of the untreated and after treatedsulphurdyeings were tested according to ISO standard methods, including fastness to washing (ISO105 CO9), rubbing (ISO-105 X12), light (ISO-105 B02) and tensile strength (ISO-13934/1 1999).

\section{RESULTS AND DISCUSSION}

\section{Investigation into the Effects of Sequential Application} of Fixapret CP and Bayprotect Cl on Wash Fastness of
Sulphur Black 1 Dyed Cotton Fabric: Fixapret CP is a DMDHEU (Dimethyldihydroxyethyleneurea) based resin. DMDHEU is highly reactive and very suitable for washresistant resin finishing. The sequential application of DMDHEU based durable press finish Fixapret $\mathrm{CP}$ and Bayprotect $\mathrm{Cl}$ was attempted to improve the resistance to oxidation of the dyes to domestic laundering and achieve sulphur dyed cotton fabric with improved wash fastness.

In order to determine the influence of Fixapret $\mathrm{CP}$ on the sulphur dyed fabric, some preliminary experiments were conducted where the finish was applied on its own as well as after Bayprotect $\mathrm{Cl}$ treatment. The concentrations and AC (Application Conditions) were selected on the basis of the manufacturer's recommendations. The exhaust and continuous method of aftertreatments were explored for after treatments with Bayprotect $\mathrm{Cl}$ and Fixapret $\mathrm{CP}$, respectively, to examine the influence of the aforementioned fixatives on wash fastness of Sulphur Black 1 dyed cotton fabric as outlined in Table 1 (AC 1-8).

The colorimetric data for untreated and after treated samples is shown in Table 2. The untreated sulphur dyed cotton fabric exhibits low resistance to bleaching and this bleach sensitivity of sulphur dyes is usually attributed to the cleavage of some of the S-S (disulphide) bonds within the complex heterocyclic macromolecules and loss of the chromophores [5]. It can be seen that the \% colour loss for untreated dyed fabric after laundering with ISO105 CO9 wash test was 59\%, however, on after treating the dyed fabric with Fixapret CP, it reduced to 27 and 18\% for $\mathrm{AC} 1$ and $\mathrm{AC} 2$, respectively.

DMDHEU based resins are produced as a result of the reaction between glyoxal, urea, and formaldehyde and react with the cellulose by etherifying the hydroxyl groups in the amorphous phase. The N-methylol groups in DMDHEU react with the cellulose, and a crosslinking net is formed [6-7]. Application of crease resist finish to cotton involves padding the material with a solution containing a condensation polymer precursor and a suitable 
polymerisation catalyst followed by drying and curing. As a result of heating, the polymer precursor either reacts with hydroxyl groups in the cellulose to form crosslinks between adjacent polymer chains, or it polymerises in the amorphous regions of the fibres [5]. Crease resist finish after treatment of sulphur dyed cotton produces crosslinked cellulose fabric and the crosslinking treatment serves to "lock" the dye in the fabric, so increasing the wash fastness [8]. In general, compared to the reference sample, Fixapret CP crosslinkedsulphur dyed fabric exhibited improved wash fastness (less colour change) against ISO-105 CO9 washing regime. However, a significant loss of color strength was observed which could be attributed to the removal of surface dye as a result of after treatment with the finish. Further, the effect on the color of the dyeing was to produce a duller tone fabric. On comparing the laundered samples, it is observed that the color strength of the finished fabric was higher than the untreated sample. Hence the durable press finished fabric exhibited improved wash fastness than the untreated.
After treatments with the tannin, Bayprotect $\mathrm{Cl}$ also showed slight improvements, that is, a reduction of $\%$ color loss to 54 and $55 \%$ for AC 3 and AC4, respectively. It is quite obvious that an increase in $\%$ concentration of the applied finish did not significantly reduce the color loss, indicating that $4 \%$ omf was an optimum quantity for the after treatment.

To enhance the effect of the fixatives on the wash fastness of the dyeings, the sequential application of Bayprotect $\mathrm{Cl}$ and Fixapret $\mathrm{CP}$ was attempted. The wash fastness of the dyed fabric against the aggressive ISO-105 CO9 treatment tended to be better when a combination with the tannin (Bayprotect $\mathrm{Cl}$ ) is used. The improved wash fastness achieved as a result of the sequential application of Fixapret $\mathrm{CP}$ and Bayprotect $\mathrm{Cl}$ may be attributed to the formation of low aqueous solubility tannin/crease resist finishing agent complex. On increasing the concentration of tannin from $4-10 \%$ omf did not yield significant change in percentage color loss, hence, lower concentration of

TABLE 1. COMPOSITION AND APPLICATION PARAMETERS FOR SEQUENTIAL APPLICATION OF BAYPROTECT CL AND FIXAPRET CP ON CI LEUCO SULPHUR BLACK 1 DYED COTTON FABRIC

\begin{tabular}{|c|c|c|c|c|c|}
\hline \multirow{2}{*}{$\begin{array}{r}\text { Application } \\
\text { Conditions }\end{array}$} & \multicolumn{4}{|c|}{ Concentrations } & \multirow{2}{*}{$\begin{array}{l}\text { Application } \\
\text { Procedure }\end{array}$} \\
\hline & $\begin{array}{c}\text { Fixapret CP } \\
(\mathrm{g} / \mathrm{L})\end{array}$ & $\begin{array}{c}\text { Magnesium Chloride } \\
(\mathrm{g} / \mathrm{L})\end{array}$ & $\begin{array}{l}\text { Bayprotect } \\
\mathrm{Cl}(\% \text { omf })\end{array}$ & $\begin{array}{c}\text { Sodium Sulphate } \\
(\mathrm{g} / \mathrm{L})\end{array}$ & \\
\hline AC-1 & 60 & 12 & - & - & Pad-Dry-Cure \\
\hline $\mathrm{AC}-2$ & 120 & 24 & - & - & Pad-Dry-Cure \\
\hline $\mathrm{AC}-3$ & - & - & 4 & 100 & $98^{\circ} \mathrm{C}, 20$ minutes \\
\hline $\mathrm{AC}-4$ & - & - & 10 & 100 & $98^{\circ} \mathrm{C}, 20$ minutes \\
\hline \multirow{2}{*}{$\mathrm{AC}-5$} & - & - & 4 & 100 & $98^{\circ} \mathrm{C}, 20$ minutes \\
\hline & 60 & 12 & - & - & Pad-Dry-Cure \\
\hline \multirow{2}{*}{ AC- 6} & - & - & 4 & 100 & $98^{\circ} \mathrm{C}, 20$ minutes \\
\hline & 120 & 24 & - & - & Pad-Dry-Cure \\
\hline \multirow{2}{*}{$\mathrm{AC}-7$} & - & - & 10 & 100 & $98^{\circ} \mathrm{C}, 20$ minutes \\
\hline & 60 & 12 & - & - & Pad-Dry-Cure \\
\hline \multirow{2}{*}{$\mathrm{AC}-8$} & - & - & 10 & 100 & $98^{\circ} \mathrm{C}, 20$ minutes \\
\hline & 120 & 24 & - & - & Pad-Dry-Cure \\
\hline
\end{tabular}

Mehran University Research Journal of Engineering \& Technology, Volume 38, No. 2, April, 2019 [p-ISSN: 0254-7821, e-ISSN: 2413-7219] 
Bayprotect $\mathrm{Cl}$ ( $4 \%$ omf) was chosen for further investigations. Therefore, the combination of $4 \% \mathrm{omf}$ Bayprotect $\mathrm{Cl}$ and $120 \mathrm{~g} / \mathrm{L}$ Fixapret CP (AC 4) may best be suited for protection against ISO-1O5 CO9 washing.

Application of Fixapret CP (AC 1 and AC 2) on sulphur dyed fabric caused the fabric to become yellower and also reduced the chroma. When the fabric was subjected to sequential application of the two reagents, the dyed fabric tended to be redder and yellower, and the chroma was further reduced. Since Fixapret CP finished fabric undergoes shade changes when exposed to bleaching environment, this change was further enhanced due to Bayprotect $\mathrm{Cl}$ treatment. This is presumably due to the characteristic yellowish brown color of the anionic tannin based product.

\section{Investigation into the Effects of Sequential Application} of Bayprotect Cl, Fixapret CP moreover, CC on Wash Fastness of Sulphur Black 1 Dyed Cotton Fabric: A single finish containing crosslinker, acid catalyst and quaternary ammonium compounds have been formerly used for differential treatments of cotton fabric. The finished, dried and cured fabric was partly crosslinked and cationic and

TABLE 2. COLORIMETRIC DATA FOR ISO 105 CO9 WASHED CI LEUCO SULPHUR BLACK 1 DYED COTTON FABRIC AFTERTREATED WITH BAYPROTECT CLAND FIXAPRET CP

\begin{tabular}{|c|c|c|c|c|c|c|c|c|c|}
\hline $\begin{array}{c}\text { Washing } \\
\text { Treatment }\end{array}$ & $\mathrm{L}^{*}$ & $a^{*}$ & $\mathrm{~b}^{*}$ & $\mathrm{c}^{*}$ & $\mathrm{~h}$ & $\mathrm{~K} / \mathrm{S}$ & $\begin{array}{c}\text { Colour Loss } \\
(\%)\end{array}$ & GS Rating & $\mathrm{DE}$ \\
\hline Untreated & 30.9 & -1.3 & -4.5 & 4.6 & 254.0 & 7.4 & - & - & - \\
\hline laundered & 43.8 & -2.0 & -3.6 & 4.1 & 241.5 & 3.0 & $59 \%$ & 1 & 12.9 \\
\hline AC-1 & \multicolumn{9}{|c|}{$60 \mathrm{~g} / \mathrm{L}$ Fixapret $\mathrm{CP}+12 \mathrm{~g} / \mathrm{L}$ Magnesium Chloride (PDC) } \\
\hline Aftertreated & 33.7 & -1.3 & -3.4 & 3.7 & 248.8 & 5.9 & - & - & - \\
\hline laundered & 38.2 & -1.8 & -2.3 & 2.9 & 233.2 & 4.3 & $27 \%$ & $2 / 3$ & 4.7 \\
\hline $\mathrm{AC}-2$ & \multicolumn{9}{|c|}{$120 \mathrm{~g} / \mathrm{L}$ Fixapret $\mathrm{CP}+24 \mathrm{~g} / \mathrm{L}$ Magnesium Chloride (PDC) } \\
\hline Aftertreated & 34.3 & -1.3 & -3.3 & 3.6 & 248.3 & 5.7 & - & - & - \\
\hline laundered & 37.1 & -1.8 & -2.7 & 3.2 & 237.0 & 4.7 & $18 \%$ & $3 / 4$ & 2.9 \\
\hline AC-3 & \multicolumn{9}{|c|}{$4 \%$ omf Bayprotect $\mathrm{Cl}+100 \mathrm{~g} / \mathrm{L}$ Sodium Sulphate $\left(98^{\circ} \mathrm{C}, 20\right.$ minutes $)$} \\
\hline Aftertreated & 31.5 & -0.5 & -4.0 & 4.0 & 262.7 & 6.8 & - & - & - \\
\hline laundered & 43.3 & -1.7 & -3.6 & 4.0 & 244.2 & 3.1 & $54 \%$ & 1 & 11.6 \\
\hline $\mathrm{AC}-4$ & \multicolumn{9}{|c|}{$10 \%$ omf Bayprotect $\mathrm{Cl}+100 \mathrm{~g} / \mathrm{L}$ Sodium Sulphate $\left(98^{\circ} \mathrm{C}, 20\right.$ minutes } \\
\hline Aftertreated & 31.2 & -0.5 & -4.0 & 4.0 & 263.1 & 6.9 & - & - & - \\
\hline laundered & 43.3 & -1.8 & -3.8 & 4.2 & 244.8 & 3.1 & $55 \%$ & 1 & 11.8 \\
\hline \multirow{2}{*}{ AC-5 } & \multicolumn{9}{|c|}{$4 \%$ omf Bayprotect $\mathrm{Cl}+100 \mathrm{~g} / \mathrm{L}$ Sodium Sulphate $\left(98^{\circ} \mathrm{C}, 20\right.$ minutes $)$} \\
\hline & \multicolumn{9}{|c|}{$60 \mathrm{~g} / \mathrm{L}$ Fixapret $\mathrm{CP}+12 \mathrm{~g} / \mathrm{L}$ Magnesium Chloride (PDC) } \\
\hline Aftertreated & 33.7 & -0.9 & -2.9 & 3.1 & 252.4 & 5.8 & - & - & - \\
\hline laundered & 35.7 & -1.9 & -2.2 & 3.0 & 229.2 & 5.1 & $12 \%$ & $3 / 4$ & 2.4 \\
\hline \multirow{2}{*}{ AC- 6} & \multicolumn{9}{|c|}{$4 \%$ omf Bayprotect $\mathrm{Cl}+100 \mathrm{~g} / \mathrm{L}$ Sodium Sulphate $\left(98^{\circ} \mathrm{C}, 20\right.$ minutes $)$} \\
\hline & \multicolumn{9}{|c|}{$120 \mathrm{~g} / \mathrm{L}$ Fixapret $\mathrm{CP}+24 \mathrm{~g} / \mathrm{L}$ Magnesium Chloride (PDC) } \\
\hline Aftertreated & 33.2 & -0.9 & -2.7 & 2.9 & 251.5 & 6.0 & - & - & - \\
\hline laundered & 35.1 & -1.9 & -2.3 & 3.0 & 230.1 & 5.4 & $10 \%$ & $3 / 4$ & 2.2 \\
\hline \multirow{2}{*}{ AC-7 } & \multicolumn{9}{|c|}{$10 \%$ omf Bayprotect $\mathrm{Cl}+100 \mathrm{~g} / \mathrm{L}$ Sodium Sulphate $\left(98^{\circ} \mathrm{C}, 20\right.$ minutes $)$} \\
\hline & \multicolumn{9}{|c|}{$60 \mathrm{~g} / \mathrm{L}$ Fixapret $\mathrm{CP}+12 \mathrm{~g} / \mathrm{L}$ Magnesium Chloride (PDC) } \\
\hline Aftertreated & 33.2 & -0.9 & -2.9 & 3.0 & 252.1 & 6.0 & - & - & - \\
\hline WF 3 & 35.0 & -2.1 & -2.2 & 3.1 & 225.9 & 5.4 & $10 \%$ & $3 / 4$ & 2.4 \\
\hline \multirow{2}{*}{ AC- 8} & \multicolumn{9}{|c|}{$10 \%$ omf Bayprotect $\mathrm{Cl}+100 \mathrm{~g} / \mathrm{L}$ Sodium Sulphate $\left(98^{\circ} \mathrm{C}, 20\right.$ minutes $)$} \\
\hline & \multicolumn{9}{|c|}{$120 \mathrm{~g} / \mathrm{L}$ Fixapret $\mathrm{CP}+24 \mathrm{~g} / \mathrm{L}$ Magnesium Chloride (PDC) } \\
\hline Aftertreated & 33.4 & -1.0 & -2.8 & 2.9 & 250.5 & 5.9 & - & - & - \\
\hline Laundered & 35.4 & -2.1 & -2.1 & 3.0 & 224.5 & 5.3 & $10 \%$ & $3 / 4$ & 2.4 \\
\hline
\end{tabular}

Mehran University Research Journal of Engineering \& Technology, Volume 38, No. 2, April, 2019 [p-ISSN: 0254-7821, e-ISSN: 2413-7219] 
partly untreated cotton. The fabric was dyed with different dyes and under different $\mathrm{pH}$ conditions to produce twocolor and contrasting tonal effects. The purpose of using a reactive additive in the crosslinking system was to produce additional properties in the crosslinked fabric other than resiliency and shrinkage control [9].

Previous work on modification of electrical resistivity of durable press finishes showed that cationic groups could be introduced into the finished cotton by the covalent attachment of choline along with the crosslinking agent. The combination of a crosslinking agent and CC applied through PDC method was useful in binding choline to the cotton fabric. This fabric was capable of higher uptake of CI Reactive Red 2 under acidic conditions in the absence of salt. Thus CC-treated fabrics were capable of increasing exhaustion of reactive dyes in the absence of salt and in fact the addition of salt reduced the dye uptake. The dyeing of CC-grafted cotton fabric under acidic conditions gave the highest color yields and improved wash fastness [8].

To improve the wash fastness of sulphur dyed cotton fabric, a sequential application of Bayprotect $\mathrm{Cl}$ followed by a combination of Fixapret $\mathrm{CP}$ and $\mathrm{CC}$ (a cationic reactant) was also studied. CC is a quaternary amine salt; it dissociates in water into the corresponding positively charged quaternary hydroxyl alkylammonium ion and the negatively charged chloride ion. According to OECDCriteria (Organization for Economic Cooperation and Development), it is readily biodegradable [10]. It imparts a cationic charge to cotton fabric and enhances the reactivity of anionic dye when used in combination with resins [11].

The purpose of using choline chloride with Fixapret CP was to impart cationic charge to the fabric to improve the wash fastness of the dyed fabric the aggressive ISO-1O5 CO9 washing regime. While keeping the amount of Bayprotect $\mathrm{Cl}$ and Fixapret $\mathrm{CP}$ constant, three combinations were investigated with increasing concentrations of CC. $\mathrm{CC}$ was added into the finish bath containing Fixapret $\mathrm{CP}$ and magnesium chloride and applied through PAC method. AC-6 was used as the base formulation owing to the observed improved protection against oxidative bleaches in household laundering conditions. AC-9, AC-10 and AC-11 contains 1, 10 and 60 $\mathrm{g} / \mathrm{L}$ of CC, respectively, together with the base formulation (Table 3).

Sequential application of a crosslinking agent after tannin treatment has improved fastness for ISO-1O5 CO9; however, it tended to reduce the chroma when compared to the individual application of the crosslinking agent to the sulphur dyed fabric. The co-application of choline

TABLE 3. COMPOSITION AND APPLICATION PARAMETERS FOR SEQUENTIAL APPLICATION OF BAYPROTECT CL, FIXAPRET CP AND CHOLINE CHLORIDE ON CI LEUCO SULPHUR BLACK 1 DYED COTTON FABRIC

\begin{tabular}{|c|c|c|c|c|c|c|}
\hline \multirow{2}{*}{$\begin{array}{l}\text { Application } \\
\text { Conditions }\end{array}$} & \multicolumn{5}{|c|}{ Concentrations } & \multirow{2}{*}{$\begin{array}{c}\text { Application } \\
\text { Procedure }\end{array}$} \\
\hline & $\begin{array}{l}\text { Fixapret CP } \\
(\mathrm{g} / \mathrm{L})\end{array}$ & $\begin{array}{c}\text { Magnesium Chloride } \\
(\mathrm{g} / \mathrm{L})\end{array}$ & $\begin{array}{c}\text { Choline Chloride } \\
(\mathrm{g} / \mathrm{L})\end{array}$ & $\begin{array}{l}\text { Bayprotect } \mathrm{Cl} \\
\text { (\% omf) }\end{array}$ & $\begin{array}{c}\text { Sodium Sulphate } \\
(\mathrm{g} / \mathrm{L})\end{array}$ & \\
\hline \multirow{2}{*}{ AC-9 } & - & - & - & 4 & 100 & $98^{\circ} \mathrm{C}, 20$ minutes \\
\hline & 120 & 24 & 1 & - & - & Pad-Dry-Cure \\
\hline \multirow{2}{*}{ AC- 10} & - & - & - & 4 & 100 & $98^{\circ} \mathrm{C}, 20$ minutes \\
\hline & 120 & 24 & 10 & - & - & Pad-Dry-Cure \\
\hline \multirow{2}{*}{ AC-11 } & - & - & - & 4 & 100 & $98^{\circ} \mathrm{C}, 20$ minutes \\
\hline & 120 & 24 & 60 & - & - & Pad-Dry-Cure \\
\hline
\end{tabular}

Mehran University Research Journal of Engineering \& Technology, Volume 38, No. 2, April, 2019 [p-ISSN: 0254-7821, e-ISSN: 2413-7219] 
chloride and Fixapret CP after tannin treatment did not considerably enhance the wash fastness of the dyed samples (AC 9-AC 11, Table 4). In fact, on increasing the concentration of CC (AC-10 and AC-11), the color strength of ISO-105 CO9 washed fabric was reduced which resulted in an increased color loss. The possible reason for this could be desorption of the dye from the fabric surface as a result of higher concentrations of choline chloride and Fixapret CP.

\section{Investigation into the Application of Relative Proportions} of Bayprotect Cl, Fixapret CP and CC on Wash Fastness of Sulphur Black 1 Dyed Cotton Fabric: The crease resistant finish, Fixapret $\mathrm{CP}$ was found to produce deleterious effect on the shade of the dyed fabric when used in high concentrations (AC-2, Table 2), therefore, smaller quantities of Fixapret $\mathrm{CP}$ were introduced in the finish bath with a range of $\mathrm{CC}$ concentrations while keeping Bayprotect $\mathrm{Cl}$ fixed at $4 \%$ omf. The amount of Fixapret CP introduced was 10-30 g/L while different concentrations of CC $(20,30$ and $50 \mathrm{~g} / \mathrm{L})$ were also added to investigate the comparative impact on the after treated fabrics (Table 5).

On applying various combinations of the aforementioned fixatives, only slight improvements were observed, as shown in Table 6. Hence, the co-application of CC with relative proportions of Fixapret $\mathrm{CP}$ was not found to be much significant for improving the resistance of the dyes to oxidation against perborate based laundering.

\section{Application of Reduced Concentrations of Bayprotect Cl,} Fixapret $\mathbf{C P}$, and $\mathbf{C C}$ : In order to reduce the hazardous environmental effects produced as a result of formaldehyde present in higher concentrations (60 and $120 \mathrm{~g} / \mathrm{l}$ ) of Fixapret CP and adverse influence of the same on the chroma, handle and shade of the dyed fabric, lower quantity of Fixapret CP $(10 \mathrm{~g} / \mathrm{L})$ was co-applied with CC $(10-20 \mathrm{~g} / 1)$ to the finish bath. While keeping AC-18 as the base formulation, AC-19 and AC-20 were conducted with

TABLE 4. COLORIMETRIC DATA FOR ISO 105 CO9 WASHED CI LEUCO SULPHUR BLACK 1 DYED COTTON FABRIC AFTERTREATED WITH BAYPROTECT CL, FIXAPRET CP AND VARYING CONCENTRATIONS OF CHOLINE CHLORIDE

\begin{tabular}{|c|c|c|c|c|c|c|c|c|c|}
\hline $\begin{array}{c}\text { Washing } \\
\text { Treatment } \\
\end{array}$ & $\mathrm{L}^{*}$ & $a^{*}$ & $b^{*}$ & $\mathrm{c}^{*}$ & $\mathrm{~h}$ & $\mathrm{~K} / \mathrm{S}$ & $\begin{array}{c}\text { Colour Loss } \\
(\%)\end{array}$ & GS Rating & $\mathrm{DE}$ \\
\hline \multirow{2}{*}{ AC-9 } & \multicolumn{9}{|c|}{$4 \%$ omf Bayprotect $\mathrm{Cl}+100 \mathrm{~g} / \mathrm{L}$ Sodium Sulphate $\left(98^{\circ} \mathrm{C}, 20\right.$ minutes $)$} \\
\hline & \multicolumn{9}{|c|}{$120 \mathrm{~g} / \mathrm{L}$ Fixapret $\mathrm{CP}+24 \mathrm{~g} / \mathrm{L}$ Magnesium Chloride $+1 \mathrm{~g} / \mathrm{L}$ Choline Chloride (PDC) } \\
\hline Aftertreated & 33.0 & -0.7 & -3.1 & 3.2 & 257.4 & 6.0 & - & - & - \\
\hline Laundered & 35.4 & -1.8 & -2.3 & 2.9 & 232.5 & 5.3 & $12 \%$ & $3 / 4$ & 2.7 \\
\hline \multirow{2}{*}{$\mathrm{AC}-10$} & \multicolumn{9}{|c|}{$4 \%$ omf Bayprotect $\mathrm{Cl}+100 \mathrm{~g} / \mathrm{L}$ Sodium Sulphate $\left(98^{\circ} \mathrm{C}, 20\right.$ minutes $)$} \\
\hline & \multicolumn{9}{|c|}{$120 \mathrm{~g} / \mathrm{L}$ Fixapret $\mathrm{CP}+24 \mathrm{~g} / \mathrm{L}$ Magnesium Chloride $+10 \mathrm{~g} / \mathrm{L}$ Choline Chloride (PDC) } \\
\hline Aftertreated & 33.7 & -0.7 & -3.1 & 3.1 & 256.7 & 5.8 & - & - & - \\
\hline Laundered & 38.6 & -1.9 & -0.9 & 2.1 & 205.1 & 4.2 & $28 \%$ & $2 / 3$ & 5.7 \\
\hline \multirow{2}{*}{ AC-11 } & \multicolumn{9}{|c|}{$4 \%$ omf Bayprotect $\mathrm{Cl}+100 \mathrm{~g} / \mathrm{L}$ Sodium Sulphate (98oC, 20 minutes) } \\
\hline & \multicolumn{9}{|c|}{ 120g/L Fixapret CP $+24 \mathrm{~g} / \mathrm{L}$ Magnesium Chloride $+60 \mathrm{~g} / \mathrm{L}$ Choline Chloride (PDC) } \\
\hline Aftertreated & 33.5 & -0.7 & -3.1 & 3.1 & 256.7 & 5.8 & - & - & - \\
\hline Laundered & 38.6 & -1.9 & -0.9 & 2.1 & 205.1 & 4.2 & $28 \%$ & $2 / 3$ & 5.7 \\
\hline
\end{tabular}

Mehran University Research Journal of Engineering \& Technology, Volume 38, No. 2, April, 2019 [p-ISSN: 0254-7821, e-ISSN: 2413-7219] 
different proportions of CC (10 and $20 \mathrm{~g} / \mathrm{l})$ applied on Bayprotect $\mathrm{Cl}$ after treated fabric. Isolating the process from Fixapret $\mathrm{CP}$, after treatments with the sequential application of Bayprotect $\mathrm{Cl}$ followed by $\mathrm{CC}$ (AC-21 and AC-22) were also conducted. The application conditions are outlined in Table 7.

TABLE 5. COMPOSITION AND APPLICATION PARAMETERS FOR BAYPROTECT CL, FIXAPRET CP AND CHOLINE CHLORIDE ON CI LEUCO SULPHUR BLACK 1 DYED COTTON FABRIC

\begin{tabular}{|c|c|c|c|c|c|c|}
\hline \multirow{2}{*}{$\begin{array}{l}\text { Application } \\
\text { Conditions }\end{array}$} & \multicolumn{5}{|c|}{ Concentrations } & \multirow{2}{*}{$\begin{array}{l}\text { Application } \\
\text { Procedure }\end{array}$} \\
\hline & $\begin{array}{c}\text { Fixapret CP } \\
(\mathrm{g} / \mathrm{L})\end{array}$ & $\begin{array}{c}\text { Magnesium Chloride } \\
(\mathrm{g} / \mathrm{L})\end{array}$ & $\begin{array}{c}\text { Choline Chloride } \\
\text { (g/L) }\end{array}$ & $\begin{array}{l}\text { Bayprotect } \mathrm{Cl} \\
\text { (\% omf) }\end{array}$ & $\begin{array}{c}\text { Sodium Sulphate } \\
(\mathrm{g} / \mathrm{L})\end{array}$ & \\
\hline $\mathrm{AC}-12$ & 10 & 2 & - & - & - & PDC \\
\hline \multirow{2}{*}{$\mathrm{AC}-13$} & - & - & - & 4 & 100 & $98^{\circ} \mathrm{C}, 20$ minutes \\
\hline & 10 & 2 & 20 & - & - & PDC \\
\hline \multirow{2}{*}{$\mathrm{AC}-14$} & - & - & - & 4 & 100 & $98^{\circ} \mathrm{C}, 20$ minutes \\
\hline & 20 & 4 & 20 & - & - & PDC \\
\hline \multirow{2}{*}{$\mathrm{AC}-15$} & - & - & - & 4 & 100 & $98^{\circ} \mathrm{C}, 20$ minutes \\
\hline & 20 & 4 & 30 & - & - & PDC \\
\hline \multirow{2}{*}{$\mathrm{AC}-16$} & - & - & - & 4 & 100 & $98^{\circ} \mathrm{C}, 20$ minutes \\
\hline & 30 & 6 & 30 & - & - & PDC \\
\hline \multirow{2}{*}{$\mathrm{AC}-17$} & - & - & - & 4 & 100 & $98^{\circ} \mathrm{C}, 20$ minutes \\
\hline & 25 & 5 & 50 & - & - & PDC \\
\hline
\end{tabular}

TABLE 6. COLORIMETRIC DATA FOR ISO 105 CO9 WASHED CI LEUCO SULPHUR BLACK 1 DYED COTTON FABRIC AFTERTREATED WITH BAYPROTECT CL, FIXAPRET CP AND CHOLINE CHLORIDE

\begin{tabular}{|c|c|c|c|c|c|c|c|c|c|}
\hline $\begin{array}{c}\text { Washing } \\
\text { Treatment }\end{array}$ & $\mathrm{L}^{*}$ & $a^{*}$ & $b^{*}$ & $\mathrm{c}^{*}$ & $\mathrm{~h}$ & $\mathrm{~K} / \mathrm{S}$ & $\begin{array}{c}\text { Colour Loss } \\
(\%)\end{array}$ & GS Rating & $\mathrm{DE}$ \\
\hline $\mathrm{AC}-12$ & \multicolumn{9}{|c|}{$10 \mathrm{~g} / \mathrm{L}$ Fixapret $\mathrm{CP}+2 \mathrm{~g} / \mathrm{L}$ Magnesium Chloride (PDC) } \\
\hline Aftertreated & 29.8 & -1.0 & -3.8 & 3.9 & 255.8 & 7.9 & - & - & - \\
\hline laundered & 38.7 & -1.6 & -2.5 & 3.0 & 236.6 & 4.2 & $47 \%$ & $1 / 2$ & 9.1 \\
\hline \multirow{2}{*}{$\mathrm{AC}-13$} & \multicolumn{9}{|c|}{$4 \%$ om fBayprotect $\mathrm{Cl}+100 \mathrm{~g} / \mathrm{L}$ Sodium Sulphate $\left(98^{\circ} \mathrm{C}, 20\right.$ minutes $)$} \\
\hline & \multicolumn{9}{|c|}{$10 \mathrm{~g} / \mathrm{L}$ Fixapret $\mathrm{CP}+2 \mathrm{~g} / \mathrm{L}$ Magnesium Chloride $+20 \mathrm{~g} / \mathrm{L}$ Choline Chloride (PDC) } \\
\hline Aftertreated & 32.9 & -0.5 & -3.5 & 3.6 & 261.5 & 6.1 & - & - & - \\
\hline laundered & 42.5 & -1.7 & -1.3 & 2.2 & 217.8 & 3.2 & $48 \%$ & $1 / 2$ & 9.9 \\
\hline \multirow{2}{*}{$\mathrm{AC}-14$} & \multicolumn{9}{|c|}{$4 \%$ omf Bayprotect $\mathrm{Cl}+100 \mathrm{~g} / \mathrm{L}$ Sodium Sulphate $\left(98^{\circ} \mathrm{C}, 20\right.$ minutes $)$} \\
\hline & \multicolumn{9}{|c|}{$20 \mathrm{~g} / \mathrm{L}$ Fixapret $\mathrm{CP}+4 \mathrm{~g} / \mathrm{L}$ Magnesium Chloride $+20 \mathrm{~g} / \mathrm{L}$ Choline Chloride (PDC) } \\
\hline Aftertreated & 34.4 & -0.5 & -3.4 & 3.5 & 262.0 & 5.4 & - & - & - \\
\hline WF 3 & 42.9 & -1.7 & -1.5 & 2.3 & 221.3 & 3.2 & $41 \%$ & $1 / 2$ & 8.8 \\
\hline \multirow{2}{*}{$\mathrm{AC}-15$} & \multicolumn{9}{|c|}{$4 \%$ omf Bayprotect $\mathrm{Cl}+100 \mathrm{~g} / \mathrm{L}$ Sodium Sulphate $\left(98^{\circ} \mathrm{C}, 20\right.$ minutes $)$} \\
\hline & \multicolumn{9}{|c|}{$20 \mathrm{~g} / \mathrm{L}$ Fixapret $\mathrm{CP}+4 \mathrm{~g} / \mathrm{L}$ Magnesium Chloride $+30 \mathrm{~g} / \mathrm{L}$ Choline Chloride (PDC) } \\
\hline Aftertreated & 33.5 & -0.5 & -3.5 & 3.6 & 261.6 & 5.8 & - & - & - \\
\hline Laundered & 41.7 & -1.7 & -0.4 & 1.7 & 194.8 & 3.4 & $41 \%$ & $1 / 2$ & 8.8 \\
\hline \multirow{2}{*}{$\mathrm{AC}-16$} & \multicolumn{9}{|c|}{$4 \%$ omf Bayprotect $\mathrm{Cl}+100 \mathrm{~g} / \mathrm{L}$ Sodium Sulphate $\left(98^{\circ} \mathrm{C}, 20\right.$ minutes $)$} \\
\hline & \multicolumn{9}{|c|}{$30 \mathrm{~g} / \mathrm{L}$ Fixapret $\mathrm{CP}+6 \mathrm{~g} / \mathrm{L}$ Magnesium Chloride $+30 \mathrm{~g} / \mathrm{L}$ Choline Chloride (PDC) } \\
\hline Aftertreated & 33.5 & -0.5 & -3.4 & 3.4 & 262.0 & 5.8 & - & - & - \\
\hline Laundered & 41.8 & -1.8 & -0.9 & 2.0 & 206.4 & 3.4 & $41 \%$ & $1 / 2$ & 8.7 \\
\hline \multirow{2}{*}{$\mathrm{AC}-17$} & \multicolumn{9}{|c|}{$4 \%$ omf Bayprotect $\mathrm{Cl}+100 \mathrm{~g} / \mathrm{L}$ Sodium Sulphate $\left(98^{\circ} \mathrm{C}, 20\right.$ minutes $)$} \\
\hline & \multicolumn{9}{|c|}{$25 \mathrm{~g} / \mathrm{L}$ Fixapret $\mathrm{CP}+5 \mathrm{~g} / \mathrm{L}$ Magnesium Chloride $+50 \mathrm{~g} / \mathrm{L}$ Choline Chloride (PDC) } \\
\hline Aftertreated & 34.3 & -0.6 & -3.5 & 3.5 & 260.9 & 5.5 & - & - & - \\
\hline Laundered & 43.2 & -1.8 & 0.6 & 1.9 & 161.1 & 3.0 & $45 \%$ & $1 / 2$ & 9.9 \\
\hline
\end{tabular}

Mehran University Research Journal of Engineering \& Technology, Volume 38, No. 2, April, 2019 [p-ISSN: 0254-7821, e-ISSN: 2413-7219] 
As shown in Table 8, AC-19 and AC-20 indicated that the combined application of Fixapret $\mathrm{CP}$ and $\mathrm{CC}$ following Bayprotect $\mathrm{Cl}$ treatment did not yield any significant effect on the wash durability to the CO9 test. On the other hand, when $\mathrm{CC}$ was applied after Bayprotect $\mathrm{Cl}$ (AC-21), it produced results comparable to the individual application of Fixapret $\mathrm{CP}$ (AC-12).
However, on increasing the concentration of $\mathrm{CC}$ from $10-20 \mathrm{~g} / 1$, no decrease in \% color loss was observed indicating that $10 \mathrm{~g} / 1$ is an optimum quantity. It was established that sequential application of $4 \%$ omfBayprotect $\mathrm{Cl}$ and $10 \mathrm{~g} / 1$ of $\mathrm{CC}$ would produce improved results in terms of increased fastness to laundering.

TABLE 7. COMPOSITION AND APPLICATION PARAMETERS FOR REDUCED CONCENTRATIONS OF BAYPROTECT CL, FIXAPRET CP AND CHOLINE CHLORIDE ON CI LEUCO SULPHUR BLACK 1 DYED COTTON FABRIC

\begin{tabular}{|c|c|c|c|c|c|c|}
\hline \multirow{2}{*}{$\begin{array}{r}\text { Application } \\
\text { Conditions }\end{array}$} & \multicolumn{5}{|c|}{ Concentrations } & \multirow{2}{*}{$\begin{array}{l}\text { Application } \\
\text { Procedure }\end{array}$} \\
\hline & $\begin{array}{c}\text { Fixapret CP } \\
(\mathrm{g} / \mathrm{L})\end{array}$ & $\begin{array}{c}\text { Magnesium Chloride } \\
(\mathrm{g} / \mathrm{L})\end{array}$ & $\begin{array}{c}\text { Choline Chloride } \\
(\mathrm{g} / \mathrm{L})\end{array}$ & $\begin{array}{l}\text { Bayprotect } \mathrm{Cl} \\
\text { (\% omf) }\end{array}$ & $\begin{array}{l}\text { Sodium Sulphate } \\
(\mathrm{g} / \mathrm{L})\end{array}$ & \\
\hline \multirow{2}{*}{ AC-18 } & - & - & - & 4 & 100 & $98^{\circ} \mathrm{C}, 20$ minutes \\
\hline & 10 & 2 & - & - & - & PDC \\
\hline \multirow{2}{*}{ AC-19 } & - & - & - & 4 & 100 & $98^{\circ} \mathrm{C}, 20$ minutes \\
\hline & 10 & 2 & 10 & - & - & PDC \\
\hline \multirow{2}{*}{ AC- 20} & - & - & - & 4 & 100 & $98^{\circ} \mathrm{C}, 20$ minutes \\
\hline & 10 & 2 & 20 & - & - & PDC \\
\hline \multirow{2}{*}{$\mathrm{AC}-21$} & - & - & - & 4 & 100 & $98^{\circ} \mathrm{C}, 20$ minutes \\
\hline & - & - & 10 & - & - & PDC \\
\hline \multirow{2}{*}{$\mathrm{AC}-22$} & - & - & - & 4 & 100 & $98^{\circ} \mathrm{C}, 20$ minutes \\
\hline & - & - & 20 & - & - & PDC \\
\hline
\end{tabular}

TABLE 8. COLORIMETRIC DATA FOR ISO 105 CO9 WASHED CI LEUCO SULPHUR BLACK 1 DYED COTTON FABRIC AFTERTREATED WITH REDUCED CONCENTRATIONS OF BAYPROTECT CL, FIXAPRET CP AND CHOLINE CHLORIDE

\begin{tabular}{|c|c|c|c|c|c|c|c|c|c|}
\hline $\begin{array}{l}\text { Washing } \\
\text { Treatment }\end{array}$ & $\mathrm{L}^{*}$ & $a^{*}$ & $b^{*}$ & $\mathrm{c}^{*}$ & $\mathrm{~h}$ & $\mathrm{~K} / \mathrm{S}$ & $\begin{array}{c}\text { Colour Loss } \\
(\%)\end{array}$ & GS Rating & $\mathrm{DE}$ \\
\hline AC- 18 & \multicolumn{9}{|c|}{$\begin{array}{c}4 \% \text { omf Bayprotect } \mathrm{Cl}+100 \mathrm{~g} / \mathrm{L} \text { sodium sulphate( } 98 \mathrm{oC}, 20 \text { minutes }) \text {, } \\
10 \mathrm{~g} / \mathrm{L} \text { Fixapret } \mathrm{CP}+2 \mathrm{~g} / \mathrm{L} \text { Magnesium Chloride (PDC) }\end{array}$} \\
\hline Aftertreated & 29.9 & -0.4 & -3.5 & 3.6 & 263.4 & 7.6 & - & - & - \\
\hline laundered & 38.1 & -1.5 & -2.4 & 2.9 & 237.4 & 4.3 & $43 \%$ & $1 / 2$ & 8.4 \\
\hline AC-19 & \multicolumn{9}{|c|}{$\begin{array}{l}4 \% \text { om f Bayprotect } \mathrm{Cl}+100 \mathrm{~g} / \mathrm{L} \text { Sodium Sulphate }\left(98^{\circ} \mathrm{C}, 20 \text { minutes }\right) \text {, } \\
10 \mathrm{~g} / \mathrm{L} \text { Fixapret } \mathrm{CP}+2 \mathrm{~g} / \mathrm{L} \text { Magnesium Chloride }+10 \mathrm{~g} / \mathrm{L} \text { Choline Chloride (PDC) }\end{array}$} \\
\hline Aftertreated & 30.1 & -0.4 & -3.5 & 3.5 & 263.4 & 7.5 & - & - & - \\
\hline laundered & 38.2 & -1.5 & -2.5 & 2.9 & 238.3 & 4.3 & $43 \%$ & $1 / 2$ & 8.2 \\
\hline AC-20 & \multicolumn{9}{|c|}{$\begin{array}{l}4 \% \text { omf Bayprotect } \mathrm{Cl}+100 \mathrm{~g} / \mathrm{L} \text { Sodium Sulphate }\left(98^{\circ} \mathrm{C}, 20 \text { minutes }\right) \\
10 \mathrm{~g} / \mathrm{L} \text { Fixapret } \mathrm{CP}+2 \mathrm{~g} / \mathrm{L} \text { Magnesium Chloride }+20 \mathrm{~g} / \mathrm{L} \text { Choline Chloride (PDC) }\end{array}$} \\
\hline Aftertreated & 30.2 & -0.5 & -3.5 & 3.5 & 262.7 & 7.4 & - & - & - \\
\hline Laundered & 38.4 & -1.6 & -2.5 & 2.9 & 237.3 & 4.3 & $42 \%$ & $1 / 2$ & 8.3 \\
\hline AC-21 & \multicolumn{9}{|c|}{$4 \%$ omf Bayprotect $\mathrm{Cl}+100 \mathrm{~g} / \mathrm{L}$ Sodium Sulphate $\left(98^{\circ} \mathrm{C}, 20\right.$ minutes $), 10 \mathrm{~g} / \mathrm{L}$ Choline Chloride (PDC) } \\
\hline Aftertreated & 29.8 & -0.5 & -3.7 & 3.8 & 263.2 & 7.7 & - & - & - \\
\hline Laundered & 39.0 & -1.5 & -2.9 & 3.3 & 243.5 & 4.1 & $47 \%$ & $1 / 2$ & 9.2 \\
\hline $\mathrm{AC}-22$ & \multicolumn{9}{|c|}{$4 \%$ omf Bayprotect $\mathrm{Cl}+100 \mathrm{~g} / \mathrm{L}$ Sodium Sulphate $\left(98^{\circ} \mathrm{C}, 20\right.$ minutes), $20 \mathrm{~g} / \mathrm{L}$ Choline Chloride (PDC) } \\
\hline Aftertreated & 29.7 & -0.4 & -3.7 & 3.7 & 264.2 & 7.7 & - & - & - \\
\hline Laundered & 39.2 & -1.5 & -2.9 & 3.2 & 243.5 & 4.1 & $47 \%$ & $1 / 2$ & 9.6 \\
\hline
\end{tabular}

Mehran University Research Journal of Engineering \& Technology, Volume 38, No. 2, April, 2019 [p-ISSN: 0254-7821, e-ISSN: 2413-7219] 


\section{Effect of Aftertreatments on Tensile Strength, Light, and} Rub Fastness of CI Leuco Sulphur Black 1 Dyed Cotton

Fabric: The impact of after treatments on the light and rub fastnesses of the after treated fabrics was also evaluated and the results indicated that these treatments did not affect the light fastness and dry crocking of the dyed fabric (being 4 and 4-5 for all samples respectively, Table 9). However, it can be seen that after treatment with Fixapret CP induced detrimental effects on the wet crocking of the dyed fabric, which is a typical characteristic of the finish.

The crease resist finish plays a vital role in improving the wet fastness of sulphur dyes. The effect of after treatments with the said finishing agent on light fastness is less significant. The light fastness is either unaffected or slightly improved. On the other hand, it severely damages the mechanical properties of the fabric, leading to a lower tensile or tear strength goods with a duller tone [1-2].

The mechanical properties of the after treated samples revealed that the application of crease resistant finish concomitantly reduced the tensile strength of the fabric on increasing the concentrations of the finish from 10$120 \mathrm{~g} / \mathrm{L}$. This effect was further increased with the sequential application of the tannin followed by crease resistant finish. However, the treatment of dyed fabric with Bayprotect $\mathrm{Cl}$ and $\mathrm{CC}$ did not significantly damage the tensile strength (Table 10).

TABLE 9. LIGHT AND CROCKING FASTNESS DATA FOR CI LEUCO SULPHUR BLACK 1 DYED COTTON FABRIC AFTERTREATED WITH REDUCED CONCENTRATIONS OF FIXAPRET CP, BAYPROTECT CL AND CHOLINE CHLORIDE

\begin{tabular}{|c|c|c|c|}
\hline \multirow{2}{*}{ Aftertreatments } & \multirow{2}{*}{ Light Fastness } & Dry & Crocking Fastness \\
\cline { 3 - 4 } & & $4-5$ & $3-4$ \\
\hline Untreated (No Aftertreatment) & 4 & $4-5$ & $3-4$ \\
\hline AC-3 & 4 & $4-5$ & 3 \\
\hline AC-12 & 4 & $4-5$ & 3 \\
\hline AC-18 & 4 & $4-5$ & 3 \\
\hline AC-19 & 4 & $4-5$ & $3-4$ \\
\hline AC-20 & 4 & $4-5$ & $3-4$ \\
\hline AC-21 & 4 & $4-5$ & 3 \\
\hline AC-22 & 4 & & 3 \\
\hline
\end{tabular}

TABLE 10.EFFECTS OF AFTERTREATMENTS WITH FIXAPRET CP, BAYPROTECT CL AND CHOLINE CHLORIDE ON TENSILE PROPERTIES OF CI LEUCO SULPHUR BLACK 1 DYED COTTON FABRICS

\begin{tabular}{|c|c|c|c|c|}
\hline \multirow{2}{*}{ Samples } & \multicolumn{2}{|c|}{ Warp Direction } & \multicolumn{2}{c|}{ Weft Direction } \\
\cline { 2 - 5 } & $\begin{array}{c}\text { Tensile Strength } \\
\left(\mathrm{N} / \mathrm{mm}^{2}\right)\end{array}$ & $\begin{array}{c}\text { Tensile Extension at Break } \\
(\mathrm{mm})\end{array}$ & $\begin{array}{c}\text { Tensile Strength } \\
\left(\mathrm{N} / \mathrm{mm}^{2}\right)\end{array}$ & $\begin{array}{c}\text { Tensile Extension at Break } \\
(\mathrm{mm})\end{array}$ \\
\hline Untreated & 4.6 & 19.9 & 3.8 & 31.8 \\
\hline AC-2 & 3.7 & 12.1 & 2.5 & 14.0 \\
\hline AC-6 & 3.3 & 8.6 & 2.4 & 16.5 \\
\hline AC-12 & 3.8 & 14.1 & 3.6 & 20.9 \\
\hline AC-18 & 3.5 & 13.6 & 3.4 & 22.9 \\
\hline AC-21 & 4.1 & 14.7 & 3.4 & 23.5 \\
\hline
\end{tabular}

Mehran University Research Journal of Engineering \& Technology, Volume 38, No. 2, April, 2019 [p-ISSN: 0254-7821, e-ISSN: 2413-7219] 


\subsection{Mechanism}

The wash fastness of acid dyes on nylon can be improved by a back-tanning process in which the dyed fabric is first treated with tannic acid and then tartar emetic. The anionic tannic acid is adsorbed onto the surface of nylon by forces of attraction between the anionic tannic acid and cationic ammonium ion groups at the ends of the polymer chains of nylon. Further, on the application of tartar emetic, a film of the insoluble antimony salt of tannic acid is produced that restricts desorption of the dyes. Hence, the insoluble anionic tannic acid repels dye anions on a nylon surface after back tanning [5].

Syntans (synthetic tanning agents) are also used in place of tannins as they are less expensive and environmentally friendly. The mechanism by which syntans improve the wash fastness of acid dyes on nylon is slightly different. The anionic syntans do not form a layer like the tannic acid/tartar emetic combination, instead, they are substantive to nylon. The syntan molecules adsorb on the surface by interaction with ammonium ion sites but they cannot penetrate into the polymer because of their large molecular size. The large sized adsorbed syntan on the nylon surface inhibits the dye leakage during laundering [5]. Another theory favours the aromatic attraction of dyestuff and syntan, thus hindering the dyestuff molecules from migrating out of the fibre [12].
In the case of improved wash fastness of sulphur dyed fabric, there is a potential for the formation of large molecular size complexes with low aqueous solubility between the anionic tannin and the cationic reactant arising from the electrostatic forces of attraction between the anionic groups in the dye or the tannin and the cations. For this to occur, the dye must contain anionic group similar to the sulphonated groups in the direct dye. In spite of the fact that only little is known about the exact chemistry of the sulphur dyes, it has been proposed that some sulphur dyes may contain sulphonic acid groups [13]. Hence, the large surface area may lead to maximizing the cumulative effect of weak intermolecular forces and also the physical entrapment.

Since the process involves the sequential application of tannin and a cationic reactant, it is postulated that the application of an aromatic carboxylic acid derivative (anionic tannin) introduces anionic sites on cellulose as depicted in Fig. 4. Sequential application of cationic reactant, in turn, introduces positive charges which form complexes with the negative charges as shown in Fig. 5. The suggested reason for the improved wash fastness is that the sequential application of the tannin and cationic reactant has a tendency to produce complexes which inhibit the dissolution of dye molecules and protects the dye against ISO-105 CO9 washing regime based on modern detergent formulation.

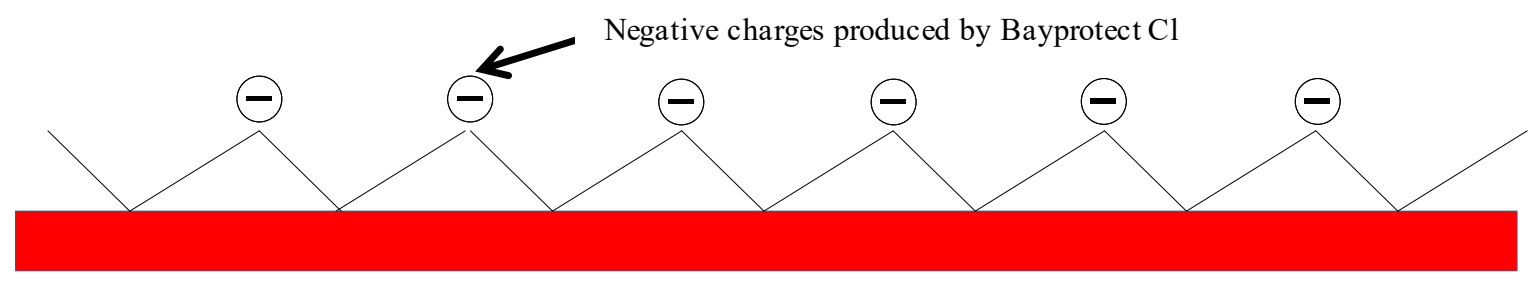

FIG. 4. FORMATION OF A LAYER OF NEGATIVE CHANGESN OF TANNIN ON THE SIRFACE OF FABRIC

Mehran University Research Journal of Engineering \& Technology, Volume 38, No. 2, April, 2019 [p-ISSN: 0254-7821, e-ISSN: 2413-7219] 


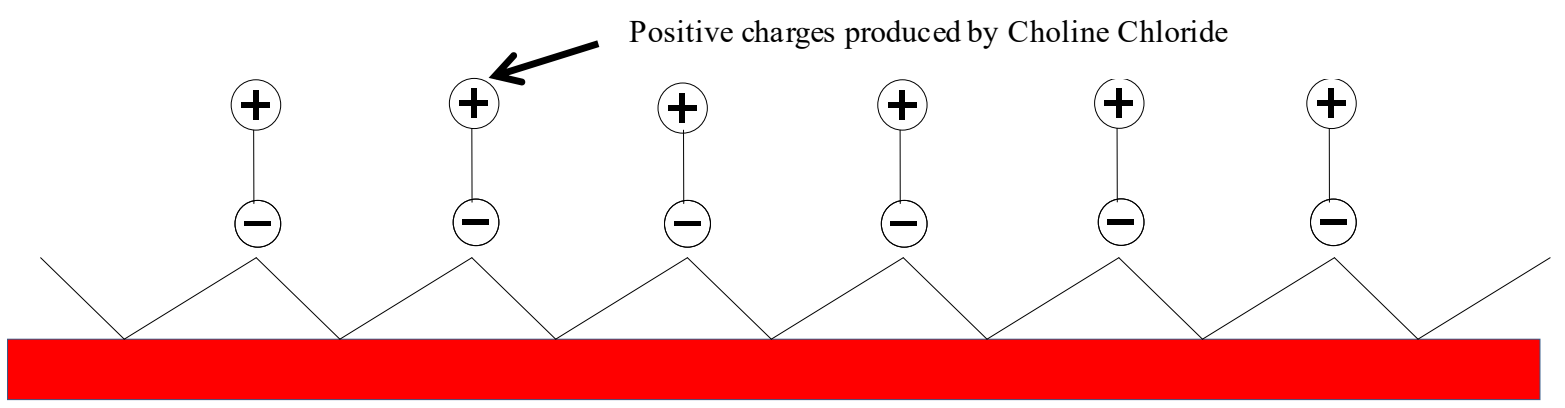

FIG. 5. FORMATION OF COMPLEXES BETWEEN TANNIN AND CATIONS

\section{CONCLUSIONS}

The sequential application of Fixapret $\mathrm{CP}$ and Bayprotect $\mathrm{Cl}$ was beneficial in terms of achieving an improved wash fastness against ISO-1O5 CO9 washing, but Fixapret CP was found to have deleterious effects on the tensile strength, wet crocking and chroma of the fabric. Furthermore, the after treatments with Fixapret CP would not lead to an eco-friendly alternative due to the presence of formaldehyde.

After treatments with various combinations of Bayprotect $\mathrm{Cl}$, Fixapret $\mathrm{CP}$ and $\mathrm{CC}$ indicated that sequential application of Bayprotect $\mathrm{Cl}$ and choline chloride appears to be comparatively better option for improving the wash fastness of sulphur dyed fabric against TAED based washing system. These results were comparable to the independent application of the crease resist finish with minimum deleterious effects on the hue, chroma and tensile properties of the fabric.

It is presumed that the improved wash fastness was due to the formation of complexes between cationic reactant (choline chloride) and anionic dye or tannin (Bayprotect $\mathrm{Cl})$ resulting in the formation of large molecular sized complexes with low aqueous solubility which are locked in the fabric.

\section{ACKNOWLEDGMENTS}

The author would like to acknowledge financial support in terms of a Ph.D. Scholarship, NED University of Engineering \& Technology, Karachi, Pakistan, through Higher Education Commission, Pakistan, to carry out this study at the School of Materials, The University of Manchester, UK.

\section{REFERENCES}

[1] Shore, J., "Cellulosics Dyeing", Society of Dyers and Colourists, pp. 280-316, Bradford, 1995.

[2] Zhou, W., and Yang, Y., "Improving the Resistance of Sulfur Dyes to Oxidation", Industrial and Engineering Chemistry Research, Volume 49, No. 10, pp. 4720-4725, Washington DC, 2010.

[3] Soliman, G., Carr, C.M., Jones, C.C., and Rigout, M., "Surface Chemical Analysis of the Effect of Extended Laundering on CI Sulphur Black 1 Dyed Cotton Fabric", Dyes and Pigments, Volume 96, No. 1, pp. 25-30, England, 2013.

[4] Burkinshaw, S.M., and Collins, G.W., "Aftertreatment to Reduce the Washdown of Leuco Sulphur Don Cotton during Repeated Washing", Journal of the Society of Dyers and Colourists, Volume 114, No. 5-6, pp. 165-168, England, 1998.

[5] Broadbent, A.D., "Basic Principles of Textile Coloration", Society of Dyers and Colorists, pp. 379-387, Bradford, 2001. 
[6] Feiz, M., and Radfar, Z., "Improvement of Wash Fastness of Direct and Acid Dyes Applied to Silk by Aftertreatment with Syntan, Syntan/Cation, and Full Backtan Processes", Iranian Polymer Journal, Volume 15, No. 4, pp. 229-305, Iran, 2006.

[7] Burkinshaw, S.M., and Kumar, N., "A Tannic Acid/Ferrous Sulfate Aftertreatment for Dyed Nylon 6, 6", Dyes and Pigments, Volume 79, No. 1, pp. 48-53, England, 2008.

[8] Lewis, D., and Mcllroy, K., "The Chemical Modification of Cellulosic Fibres to Enhance Dyeability”, Coloration Technology, Volume 27, No. 1, pp. 5-17, England, 1997.

[9] Harper Jr, R.J., "Crosslinking, Grafting and Dyeing: Finishing for Added Properties", Textile Chemist \& Colorist, Volume 23, No. 11, pp. 15-20, USA, 1991.
[10] Choline Chloride-SIDS Initial Assessment Report For SIAM 19, [May 10, 2013], Available from: http:// www.inchem.org/documents/sids/sids/67481.pdf.

[11] Cardamone, J.M., and Turner, J., "Cationic Applications for Union Dyeing Wool/Cotton Blends", Textile Chemist and Colorist and American Dyestuff Reporter, Volume 32, No. 6, pp. 49-53, USA, 2000.

[12] Schindler, W.D., and Hauser, P.J., "Chemical Finishing of Textiles", Woodhead Publishing Limited, pp. 147-148, England, 2004.

[13] Aspland, J., "Oxidation and Fixation of Reduced Sulfur Dyes", Textile Chemist and Colorist, Volume 2, No. 13, pp. 29-34, USA, 1970. 